\title{
REASONS FOR SLAGGING DURING STEMWOOD PELLET COMBUSTION AND SOME MEASURES FOR PREVENTION
}

\author{
Öhman $\mathrm{M}^{1,2}$, Nordin $\mathrm{A}^{2}$, Hedman $\mathrm{H}^{1}$, Jirjis $\mathrm{R}^{3}$ \\ ${ }^{1}$ Energy Technology Centre, PO Box 726, S-941 28 Piteå, Sweden \\ ${ }^{2}$ Department of Chemistry, Inorganic Chemistry, Umeå University, S-901 87 Umeå, \\ ${ }^{3}$ Swedish University of Agricultural Sciences, Department of Bioenergy, PO Box 7060, S-750 07 Uppsala
}

\begin{abstract}
Ash related problems have more than occasionally been observed in pellet burners during the last years. These problems lead to reduced accessibility of the appliances and also bad publicity for the pellet market. The objectives of the present work were therefore to: i) determine the critical levels of the problematic ash components in stemwood pellets regarding slagging; ii) document the variations of these problematic elements in the outgoing pellets from two pellet-mills during one operational season; iii) determine how frequently these elements exceed the critical levels; iv) determine how different sub-processes in the pelletising process (especially the dryer) effect the slagging properties of the pellet, and if possible; v) suggest some measures for prevention. Problematic and problem-free wood pellets, regarding slagging in ordinary residential pellet burners, were collected from the Swedish market. The ash compositions of these fuels were analysed and the results compiled to a database. Partial Least Square Discriminant Analysis (PLS-DA) and F-tests were used to statistically identify both the critical ash components and the critical levels of these components that separated the two reported classes. In addition, chemical equilibrium model calculations were used to interpret the findings. The variations of those elements in the in-going raw material and in the produced pellets were determined during one season in two pellet mills equipped with exhaust gas dryers. The results showed that the problematic wood-pellets had a significantly higher amount of $\mathrm{Si}$, but also $\mathrm{Al}$ and $\mathrm{Fe}$, in the fuel ash. The critical level of $\mathrm{Si}$ (given as $\mathrm{SiO}_{2}$ ) was about 20-25 weight-\% of the fuel ash, i.e. pellets with levels in or over this range resulted in slagging problems in residential burners. This critical Si content was exceeded once and twice for the analysed samples in the two studied pellet mills. In one of the studied mills, this was because of contamination by sand to the raw material during storage and handling, and in the other mill, the reason was found to be contamination of the raw material by elutriated particles from the dryer fuel. The major conclusion of the work is that both raw materials and drying fuels/processes should be carefully treated to avoid mineral contamination, and an additional cyclone separator could potentially also be used to improve the pellet quality.
\end{abstract}

Keywords: pellet fuels, raw materials, inorganic characteristics, contamination, slagging.

\section{INTRODUCTION}

Sweden’s energy supply is presently undergoing a significant conversion from the previously dominating fossil and nuclear fuels to renewable biomass fuels. The production of wood pellets in Sweden have for example increased from 10000 ton (0.05 TWh) in 1990 to 700 000 ton $(3.4 \mathrm{TWh})$ in 2001 . The pellet production was initiated for large retrofitted powderised coal boilers but now also with a substantial and increasing use in the residential small-scale market. The household consumption of pellets in stoves, burners and other residential appliances presently amount to about 0.5 $\mathrm{TWh}_{\mathrm{a}}$, and the market share is increasing extensively.

However, ash related operational problems like slagging on the grates of small-scale appliances (stoves, burners and boilers) have been reported more than occasionally. This is problematic with respect to both user comfort and performance, the latter including combustion efficiency as well as emissions. The new and small residential market is also especially susceptible to these types of problems, and the reason for the problem need to be identified for fast measures for prevention.

The results from previous work $[1,2]$ indicated that both choice of fuel and type of combustion appliance influence the amount of slag formed, while the degree of sintering was more an effect of the composition of the "fuel ash". The results also indicated on significant differences in sintering tendencies within "normal" stemwood pellets, and that the Si-content seamed to be important. Other studies [3] have shown that the ash from pure stemwood (without any contamination) should not result in any slag during normal grate operating conditions $\left(\sim 1000{ }^{\circ} \mathrm{C}\right)$ in present commercial appliances. The next task would be to determine where in the production process (handling, storage, drying, pelletisation) a potential contamination could occur.

The objectives of the present work were therefore to; (i) determine the critical levels of the problematic ash components in stemwood pellets regarding slagging; ii) document the variations of these problematic elements in the outgoing pellets from two pellet-mills during one operational season; iii) determine how frequently these elements exceed their critical levels; iv) determine how different sub-processes in the pelletising process (especially the dryer) effect the slagging properties of the pellet; and if possible v) suggest some measures for prevention.

\section{MATERIALS AND METHODS}

The work thus comprised of three different substudies; (1) compilation and evaluation of inorganic characteristics and operating experiences; (2) careful characterisation of raw materials and pellets during their flows in two pellet production units; (3) dryer gas particle sampling and analysis as well as characterisation of raw materials and final pellets when using different "drying fuels", bark and stemwood, in the combustion plant which produce the drying gases.

2.1 Compilation and evaluation of inorganic characteristics 
Inorganic characteristics of normal stemwood pellets without additives were compiled by collecting a significant number of slag and pellet samples and corresponding data of operating experiences from certified pellet appliances on the residential market. Manufacturers of pellets and pellet appliances were invited to participate in the study by sending both slagging and problem-free pellets as well as the slags, together with their answers on an inquiry. Burner and pellet characteristics were documented and the received samples (both slag and pellets) were analysed for ash content and ash forming elements (both pellets and slags) by ICP-AES and SS 187171 (pellets), respectively. Ten of the slagging, and ten of the non-slagging materials were then chosen for data analysis and evaluation by projection methods (PLS-DA) and F-tests.

2.2 Determination of variations in inorganic characteristics in raw materials and pellets from two pelletisation mills

The raw materials and pellet characteristics from two different pelletisation mills, Bioenergy in Luleå $A B$ situated in the North of Sweden and Såbi Pellets $\mathrm{AB} /$ Forsnäs situated in the South of Sweden, were studied during several months in 2000 and 2001. Both mills are equipped with exhaust gas dryers. In Luleå, a part of the produced exhaust gases from a gascombustion plant situated nearby the mill is used as drying gas. At the Såbi plant the drying gas is produced in a bark firing grate (combustion plant) which is integrated in the process. The pellet raw materials used are dominated by sawdust coming from Norway spruce at Såbi's mill and sawdust coming from Scots pine at Bionergi's mill. In both plants, the dried raw material are separated from the drying gases in a cyclone separator. The cyclone separator is located just after the rotating exhaust gas dryer. In Såbi's plant some of the drying gases are taken out after the cyclone and returned back for cooling of the hot raw gases before the raw material enter to the drying processes. The processing plants are described in more detail by Öhman et al [4]. In-going raw material, drying fuel, raw material after drying and after milling, as well as filter reject and final pellets were all sampled twice a month (sampling times correlated for estimated production lag times). Using Principal Component Analysis (PCA), a subset of 11 samples was chosen for analysis of ash content and inorganic elemental characteristics by SS 187171 and ICP-AES, respectively. Information on raw material, process operation, dryer gas and pellet quality were continuously collected and documented throughout the sampling period.

Additionally, the produced pellets were analysed for durability, compact density, bulk density, moisture content, heating value, klason lignin and total extractives. Further, the pellet raw material taken out before the dryer were analysed for moisture content and raw material samples taken out after the mill were analysed for moisture content and size fraction.

Potential correlation's between the different raw material characteristics, process-, dryer- and pelletvariables were then identified by projection to latent structures/partial least squares (PLS) analysis.

\subsection{Dryer gas particle sampling and analysis}

Particle measurements and material sampling as described in 2.2 were performed in Såbi’s mill when using bark and stemwood-chips as drying fuel. The sampling point were located before the raw material intake but after the re-circulated gas stream at a drying gas temperature of $300 \pm 20{ }^{\circ} \mathrm{C}$. Total particle concentrations were determined by isokinetic sampling using conventional equipment with quartz fiber. The particle mass size distributions $(0.03-6 \mu \mathrm{m})$ were determined by isokinetic sampling using a cascade impactor with a pre-cyclone (cut of $6 \mu \mathrm{m}$ ). An ejector dilutor was used before the impactor to dilute the gas additionally ( $\approx 7.44$ times) with clean dried air. To allow for particle mass size distribution analysis as well as extensive elemental analysis two impactor samplings for each experiment were performed. In the first, aluminum foils greased with Apiezon L vacuum grease were used as impactor substrates and in the second, isopore foils were used. Sampling probes, filter holders, pre-cyclone, ejector dilution air and impactor were all kept at $155^{\circ} \mathrm{C}$.

The impactor samples were further analysed for ash forming elements (elemental analysis) using an environmental scanning electron microscope (ESEM) equipped with an energy dispersive spectroscopy (EDS) detector.

\section{RESULTS AND DISCUSSION}

3.1 Compilation and evaluation of inorganic characteristics

A significant number of samples from both problematic and problem-free pellets were obtained from the participating manufacturers. The results from elemental bulk analysis of these materials are illustrated in Figure 1 and from the corresponding F-test in Table 1.

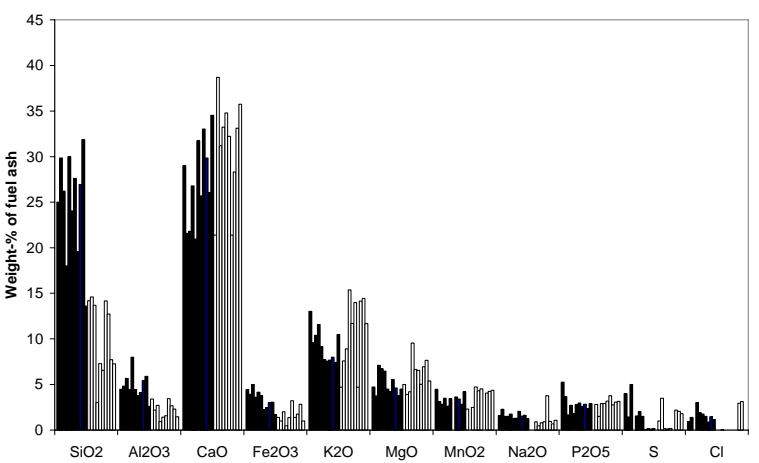

Figure 1: Fuel ash composition (given as oxides) for problematic- (black bars) and for problem-free (white bars) stemwood pellets according to their slagging tendencies in residential pellet burners.

Significant differences in inorganic characteristics between slagging and non-slagging pellets were obtained. Higher $\mathrm{Si}$, but also $\mathrm{Al}$ and $\mathrm{Fe}$ contents were found in the slagging pellets. These results are also in agreement with a previous study [1] where the same type of correlation was identified between the fraction of $\mathrm{Si}$ in the pellet fuels and the amounts of slag and deposits formed. The critical $\mathrm{Si}$ content (given as $\mathrm{SiO}_{2}$ ) seems to be in the range $20-25$ weight- $\%$ of the fuel ash. Results from chemical equilibrium model calculations in the present work further suggested increased formation of 
"sticky" silicate melt, i.e. increased slagging tendency (according to [1]), when higher $\mathrm{SiO}_{2}$ and $\mathrm{Al}_{2} \mathrm{O}_{3}$ contents were added to the fuel ash composition of normal nonslagging pellets at typical burner operating conditions. Normal stemwood without any contamination should contain very limited amounts of Si and thus, not form sticky silicates at typical temperatures in residential pellets burners $\left(1000-1100{ }^{\circ} \mathrm{C}\right)$, whereas contamination lead to the formation of sticky silicates and slagging problems.

Table 1: Significant changes in the fuel ash composition (given as oxides) between problematic and problem-free pellets.

\begin{tabular}{|ll|ll|}
\hline $\mathrm{SiO}_{2}$ & $>>$ & $\mathrm{MnO}_{2}$ & $=$ \\
\hline $\mathrm{Al}_{2} \mathrm{O}_{3}$ & $>$ & $\mathrm{Na}_{2} \mathrm{O}$ & $=$ \\
\hline $\mathrm{CaO}=$ & $\mathrm{P}_{2} \mathrm{O}_{5}$ & $=$ \\
\hline $\mathrm{Fe}_{2} \mathrm{O}_{3}$ & $>$ & $\mathrm{S}$ & $=$ \\
\hline $\mathrm{K}_{2} \mathrm{O}=$ & $\mathrm{Cl}$ & $=$ \\
\hline $\mathrm{MgO}$ & $=$ & $\begin{array}{l}\text { Ash } \\
\text { content }\end{array}$ & $>$ \\
\hline
\end{tabular}

3.2 Determination of variations in inorganic characteristics in raw materials and pellets from two pelletization mills

\section{Såbi Pellets AB/Forsnäs}

Figur 2 shows the differences between the ash content in the in-going raw materials taken out before the dryer and in the final pellets. From the figure, it can be seen that the variation in ash content of the in-going fuel has been relatively low $(0.29 \pm 0.03 \%$ of d.s.). In the beginning of the season of 2000/2001, the ash content in the analysed pellets was twice as high as in the in-going raw material. Later during the season, the ash-content in the pellet nearly reached that of the in-going raw material. These differences must be an effect of contamination of inorganic material to the raw material during the drying processes because no additives except water and steam are used in the pelletising process. Contamination of inorganic material to the raw material in the drying process has also been reported from other mills that use exhaust gases produced from combustion of woody biomass for drying [5]. In Sweden, most mills use exhaust gases produced from combustion of woody biomass for drying of the raw material.

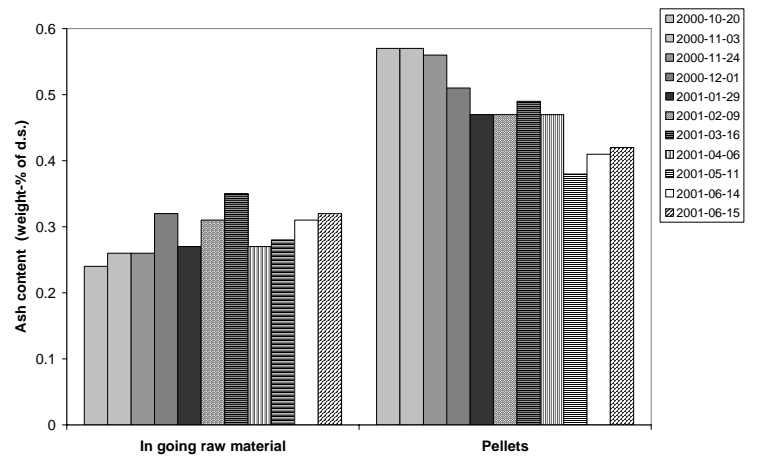

Figure 2: Differences in ash-content between in-going raw materials and final pellets.

The increase in ash content in the pellets is due to contamination of components containing $\mathrm{Si}-$, Al- and $\mathrm{Fe}$, see Figure 3. The critical Si-content, according to earlier statistical evaluation, of 20-25 weight-\% of the fuel ash (expressed as $\mathrm{SiO}_{2}$ ) was exceeded in one of the analysed samples during the operational season.

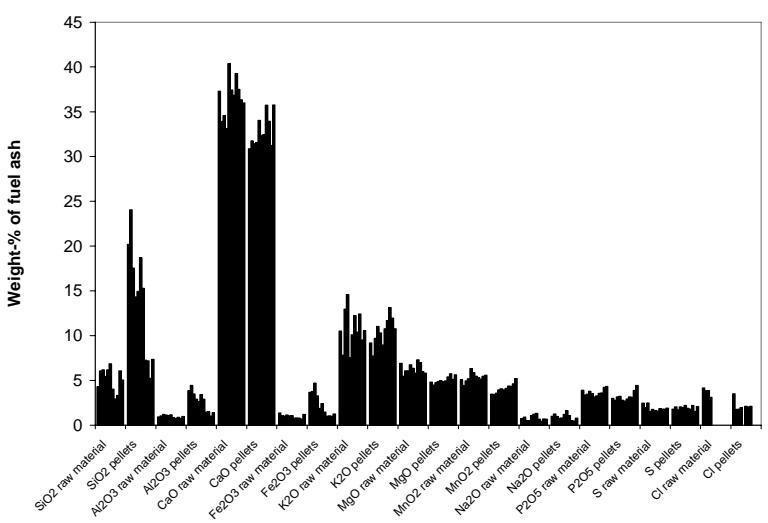

Figure 3: Differences in fuel ash composition between in-going raw materials and final pellets.

The results from the PLS-analysis showed that the ash content of the bark (drying fuel) were the variable that had strongest effect on the contamination of the inorganic compounds ( $\mathrm{Si}, \mathrm{Al}, \mathrm{Fe}$ ) to the raw material in the drying processes. Bark that had ash contents above $6 \%$ of d.s. gave rise to relatively high contamination degrees. Other variables such as primary air-flow through the grate and furnace temperature also had a significant but, relative to the ash content in the drying fuel, smaller effect. The results therefore show that the drying fuel should be treated carefully to avoid contamination and thereby minimising the slagging tendency of the produced pellets.

Bioenergy in Luleå $A B$

Figure 4 show the differences between the ash content in the in-going raw material taken out before the dryer and the final pellets. From the figure it can be seen that the variation in ash content of the in-going fuel has been relatively high $(0.32 \pm 0.12$ weight- $\%$ of d.s. $)$.

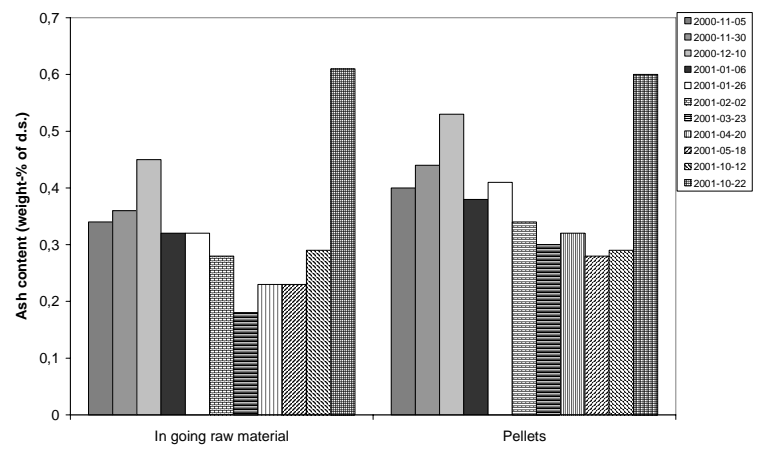

Figure 4: Differences in ash content between in-going raw materials and final pellets.

These variations seem to be an effect of the variations in the Si-content of the in-going raw material (probably because of contamination by sand/soil) even if the $\mathrm{Al}-, \mathrm{Ca}-, \mathrm{K}$, and $\mathrm{Fe}$-content also varies, but to a much lower extent (see Figure 5). Further, the ash content is often slightly higher in the final pellets than in the raw material (see Figure 4). The critical Si-content, according to earlier statistical evaluation, of $20-25$ weight- $\%$ of the 
fuel ash (expressed as $\mathrm{SiO}_{2}$ ) was exceeded in two of the analysed samples during the operational season.

The results from the PLS-analysis also confirmed that the variations in the fuel ash composition in the pellets were mostly influenced by the variation in the fuel ash composition of the in-going raw material. The results therefore show that the raw material should be treated carefully to avoid mineral contamination and thereby minimising the slagging tendency of the produced pellets.

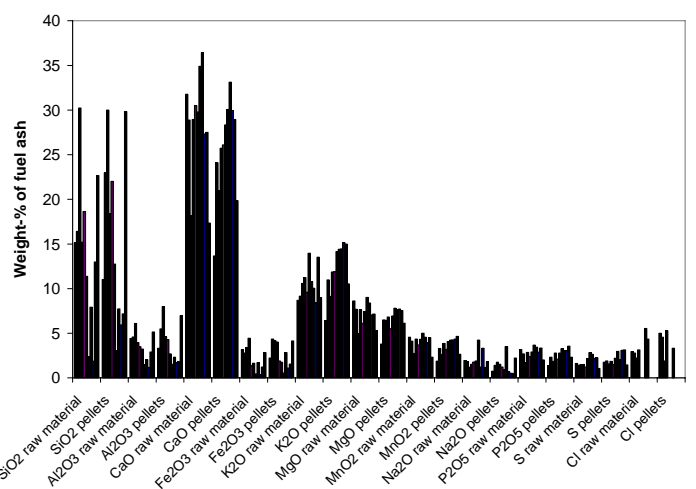

Figure 5: Differences in fuel ash composition between in-going raw materials and final pellets.

\subsection{Dryer gas sampling and analysis}

There were only small changes in the inorganic elemental characteristics between the in-going raw material and final pellets (i.e. small contamination degree in the dryer) when bark (ash content of $4.5 \%$ of d.s.) were used as drying fuel and no changes when stemwood-chips (ash content of 0.8 weight- $\%$ of d.s.) were used. However, the contamination degrees were in the same order as when bark with equal ash content were used during the "ordinary"' material sampling period of the operational season 2000/2001.

The results from the particle filter sampling showed equal total particle loads of about $100 \mathrm{mg} / \mathrm{Nm}^{3}$ when bark and stemwood-chips were used as drying fuel. The impactor samples further showed the largest mass, about $3 / 4$ of the total weight, for particles with aerodynamic diameters of $0.1-1 \mu \mathrm{m}$ for both fuels. The remaining part constitutes of particles that were caught in the precyclone. The inorganic characteristics of the sub-micron samples $(0.1-1 \mu \mathrm{m})$ is illustrated in Figure 6. The major

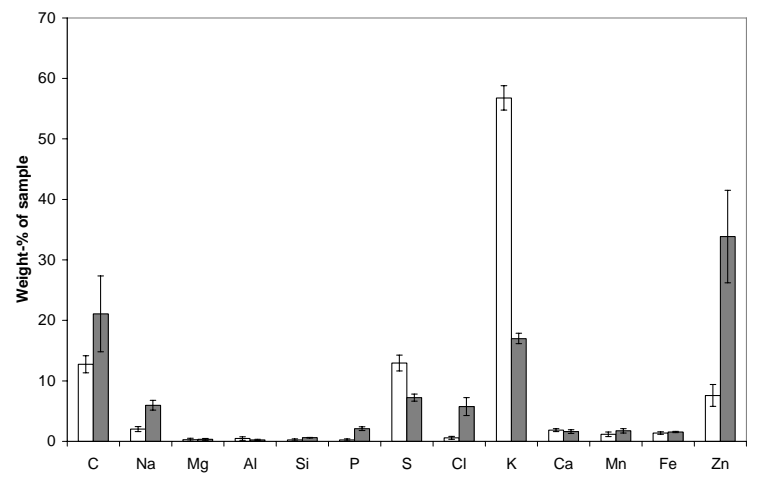

elements in the sub-micron particles are K, Zn, C, S, Na and $\mathrm{Cl}$.

Figure 6: Elemental composition of the produced submicron particles when wood chips (white bars) and bark (black bars) were used as drying fuel.

Figure 7 show a SEM image of the cyclone sample when using bark as fuel, illustrating five different typical inorganic particle types that could be identified; 1) small aggregates $(<10 \mu \mathrm{m})$ consisting of $\mathrm{Ca}, \mathrm{K}, \mathrm{Zn}, \mathrm{Cl}$ and $\mathrm{S}$; 2) spherical "larger" particles $(10-100 \mu \mathrm{m})$ mainly consisting of $\mathrm{Si}, \mathrm{Ca}, \mathrm{K}$ and $\mathrm{Al}$; 3) spherical "smaller" particles $(<10 \mu \mathrm{m})$ mainly consisting of $\mathrm{Ca}, \mathrm{P}, \mathrm{K}, \mathrm{Mn}$; 4) "larger" aggregates $(>10 \mu \mathrm{m})$ mainly consisting of $\mathrm{Ca}$, $\mathrm{Mn}, \mathrm{Mg}, \mathrm{Si}, \mathrm{Al}$ and $\mathrm{Fe}$; and 5) "sandparticles" often exceeding $100 \mu \mathrm{m}$ and mainly consisting of Si and Al. When using stemwood-chips as fuel the dominating inorganic particles in the cyclone sample were of type 1 and 2. Particles of type 5 were not found in the sample when using stemwood-chips as drying fuel.

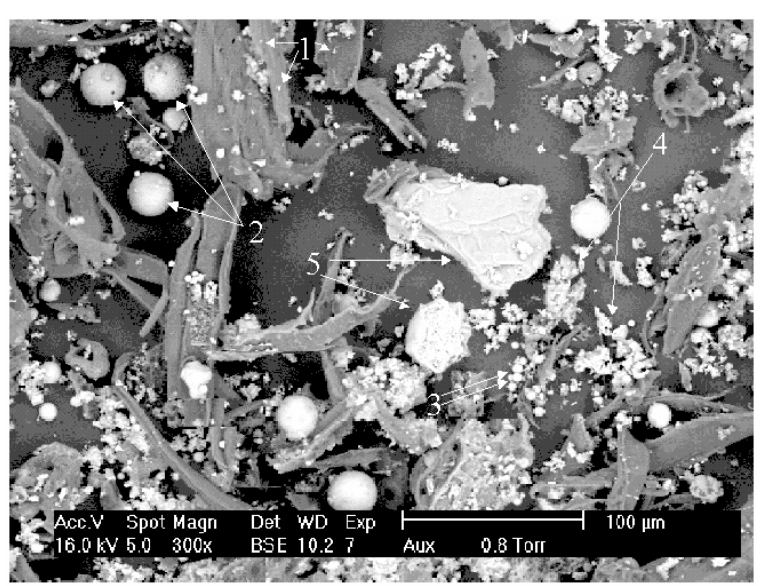

Figure 7: ESEM image showing the different typical particle "types" that were found in the cyclone sample when using bark as drying fuel.

The results from the chemical analysis of the ingoing raw material and the corresponding final pellets from the Såbi mill showed that the raw material were contaminated of components containing $\mathrm{Si}, \mathrm{Al}$ and $\mathrm{Fe}$. Further, the results from 3.2 showed that the contamination degree was highest when the ash content in the drying fuel strongly exceed the "normal"" ash content in bark [3], i.e. when it most probably was strongly contaminated with sand/soil. The contaminated sand particles in the bark are therefore most probably elutriated from the dryer fuel during combustion and separated together with the dried raw material in the cyclone separator and thereafter introduced in the pellets during pelletising. The most of the smaller particles, which are refereed as type 1-4, are not separated in the cyclone. An additional cyclone or settling chamber, placed in the raw material channel after that the raw material have been separated from the dry gases, could therefore potentially be used to improve the pellet quality.

\section{CONCLUSIONS}

The conclusions from the present work were: 
- Significant differences in inorganic characteristics between slagging and non-slagging pellets were identified. Higher $\mathrm{Si}$, but also $\mathrm{Al}$ and Fe contents were found in slagging pellets.

- The critical Si content (given as $\mathrm{SiO}_{2}$ ) was found to be 20 to 25 weight- $\%$ of the fuel ash, i.e. slagging problems were reported for higher Si contents than this.

- This critical Si content was exceeded once and twice for the analysed samples in the two participating pellet mills.

- In one of the studied mills, this was because of contamination by sand to the raw material during storage and handling, and in the other mill the reason was found to be contamination of the raw material by elutriated particles from the dryer fuel.

- The study thus showed that both raw materials and drying fuels/processes should be carefully treated to avoid mineral contamination for minimising the risk for slagging in pellets burners.

- An additional cyclone separator could also potentially be used for separation of both primary and secondary particulate contaminants, and thereby improve the pellet quality.

\section{ACKNOWLEDGEMENTS}

The operational personal at Såbi Pellets AB/Forsnäs and Bioenergy in Luleå $\mathrm{AB}$ are acknowledged for their valuable help with material sampling and process documentation. The financial support from the Swedish Energy Agency (STEM) is finally gratefully acknowledged.

\section{REFERENCES}

[1] Öhman M, Boman C, Hedman H, Nordin A, Boström D. Slagging tendencies of wood pellet ash during combustion in residential pellet burners. Submitted to Pellets 2002: $1^{\text {st }}$ World Conference on Pellets, Stockholm 2-7 September 2002

[2] Öhman M, Boman C, Hedman H, Nordin A, Pettersson E, Lethikangas P, Boström D, Westerholm R. Ash related problems and particle emissions during combustion of different pellet qualities in residential pellet burners ( $<20 \mathrm{~kW}$ ) (In Swedish). ETC-report 20002, 2000

[3] Nordin A, Chemical elemental characteristics of biomass fuels. Biomass \& Bioenergy 1994;6:339-347

[4] Öhman M, Hedman H, Nordin A, Jirjis R. The effect of the variation in ash-composition of stem-wood pellets on the slagging properies during combustion (In Swedish), ETC-report 2002-1, 2002

[5] Nilsson M. Material sampling campaign which were done during 1999 in different Swedish mills which are members of PiR-Pelletsindustrins Riksförbund 